\title{
Speed Control of Separated Excited DC Motor using Fuzzy Logic Controller
}

\author{
Muaz Abdel Rahman Ismail ${ }^{1}$, Eltahir Mohamed Heessain ${ }^{2}$ \\ ${ }^{1}$ Juba University, Department of Electronics, College of Applied and Industrial Science. Sudan \\ ${ }^{2}$ Department of Biomedical Engineering, Sudan university of Science and Technology, ALsahva zalt road, Khartom, Sudan
}

\begin{abstract}
In this paper proposed the fuzzy logic controller as an alternative solution of conventional PID controller for speed control of separated excited DC motor. Because many industrial applications need constant speed of a DC motor operation, such as paper mills, steel rolling mill...etc. But the various loads were effected on speed of DC motor, fuzzy logic controller gives better results in governing the speed control of SEDC motor, the paper used MATLAB/Simulink to simulation DC motor with fuzzy logic controller. The controller used seven memberships. Lastly, it's found that the fuzzy logic controller provided better results for improving the dynamic behavior of SEDC motor.
\end{abstract}

Keywords: DC Motor, PID Controller, Fuzzy logic controller, Chopper

\section{Introduction}

DC motor is transducer device that converts the electrical energy to mechanical energy. Many industrial applications were used such as robotic manipulators, electrical vehicles, steel rolling mills, and electrical cranes, due to simpler, less precise, higher start torque characteristic and higher response performance. To do various applications the DC motor must operate in various modes of speed specific operation the DC motor needed a controller, to control the speed of DC motor to execute the desired takes.

The major problem layout when use the DC motor is the nonlinearity characteristic of DC motor such as friction and saturation are affected on the conventional control algorithms, it degrades the performance of conventional controller.

The advance control methods such as state space methods, optimal control, state feedback, robust control:H_2, or $\mathrm{H}_{-} \infty$, method adaptive control, variance control ...e.g. this control methods bullied their design on accurate models and parameters. It's developed to reduce the nonlinearity effects, but the major problems when using these controllers the structure of system build on the effect gained as a result of disturbance and environmental conditions. It's adding more complexity to the controller system.

The advantage fuzzy control is a model free approach for design; it does not need any mathematical model strictly for the plant, because most often appropriate mathematical model of dynamical systems are not available, fuzzy control depended or based on plant operating experience, its collected knowledge from human expertise about plant operation.

In this paper proposed a fuzzy logic controller for DC motor speed control and it is tested for load torque, the designed Simulink model of fuzzy logic controller the speed control of DC motor are also tested for 5 and 7 membership number of fuzzy controller operated efficiently and give better improvement in results over PID controller[13].

\section{Previous Studies}

\subsection{Kapil Raghuvonsi, Shilpam Saxena}

The author in this paper use the fuzzy logic controller to govern the speed of separately excited DC motor on various loads .Its introduce the fuzzy logic controller as the best than PI and PID controller for solving the problem arises from load parameter changes[13].

\subsection{Mahesh Chandra Gang war, Dr. Pratibha Tiwari}

The paper used mat lab / Simulink to design separate excited DC motor. The aim of paper is to compare between conventional PID controller and fuzzy tuned PID controller it found that fuzzy tuned PID controller is improve the dynamic behavior of DC motor[14].

2.3 Shashi Bhushan Kumar, Mohammed Hasmt Ali, Anshu Sinha

This paper proposed that fuzzy logic controller as an alternative to PI and PID controllers especially when data are not available for the system, it's found that the fuzzy logic controller do better than PI and PID controllers[12].

\section{The Mathematical Model of PMDC Motor}

A DC motor consists of electrical and mechanical equation described as:

Air gap flux given as.

$$
\emptyset=K_{f} I_{f}
$$

The torque developed by the motor is given as.

$$
T_{m}=K_{t} I_{a} \emptyset
$$




\section{International Journal of Science and Research (IJSR) \\ ISSN (Online): 2319-7064}

Index Copernicus Value (2013): 6.14 | Impact Factor (2015): 6.391

The back emf of the motor

$$
e_{b}=k_{b} \omega_{m}
$$

Taking Laplace transform will get that

$$
E_{b}(s)=K_{b} S(\theta)
$$

General equation of PMDCM is given as:

$$
V_{a}=R_{a} I_{a}+L_{a} \frac{d I_{a}}{d t}+E_{b}
$$

Taking Laplace transform for equation (5).

$$
V_{a}=R_{a} I_{a}(s)+s L_{a} I_{a}(s)+E_{b}(s)
$$

From equation (4) and (6) we get .

$$
\begin{aligned}
& V_{a}(s)=R_{a} I_{a}+s L_{a} I_{a}(s)+K_{b} s \theta \\
& I_{a}(s)\left(R_{a}+s L_{a}\right)=V_{a}(s)-K_{b} s \theta(s)
\end{aligned}
$$

The Load torque equation is given as:

$$
J \frac{d^{2} \theta}{d t^{2}}+f \frac{d \theta}{d t}=T_{m}=K_{t} I_{a}
$$

Take Laplace transform for both side of equation (9)

$$
\left(J s^{2}+f s\right) \theta(s)=T_{m}(s)=k_{T} I_{a}(\mathrm{~s})
$$

From equation (10) I_a is given as.

$$
I_{a}(s)=\frac{T_{m}}{k_{T}}=\frac{\left(J s^{2}+f s\right) \theta(s)}{k_{T}}
$$

From equ. (8) and (11) we get

$$
\begin{gathered}
\frac{\left(J s^{2}+f s\right)\left(R_{a}+s L_{a}\right) \theta(s)}{K_{T}}=V_{a}(s)-K_{b} s \theta(s) \\
V_{a}(s)=\frac{\left(U s^{2}+f s\right)\left(R_{a}+s L_{a}\right) \theta(s)}{K_{T}}+K_{b} s \theta
\end{gathered}
$$

From equation (13)

Where

$$
\frac{\theta(s)}{V_{a}(s)}=\frac{K_{T}}{\left(J s^{2}+f s\right)\left(R_{a}+s L_{a}\right)+s k_{b}}
$$

$$
\begin{gathered}
R_{a}=\text { Armature resistance }(\Omega) . \\
L_{a}=\text { Armature inductance }(\mathrm{H}) . \\
I_{m}=\text { Motor of intertia }\left(\mathrm{Kg} \cdot \mathrm{m}^{2} / \mathrm{s}^{2}\right) . \\
K_{b}=\text { motor constant. } \\
f=\text { Daming frication coef ficient. }
\end{gathered}
$$

\subsection{Dynamic Model of Direct Current Motor:}

The motor connected with dynamical Load represented on figure (1).
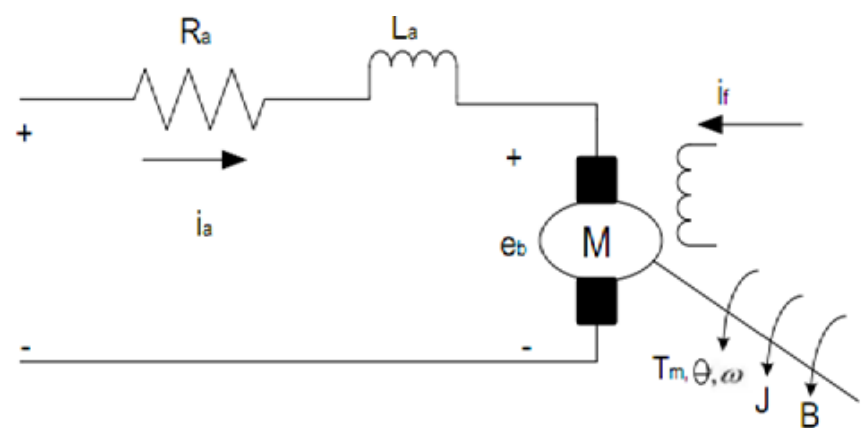

Figure 1: Show the electrical circuit of PMDC Motor with Dynamic Load

\subsection{Driver circuit}

In DC motor speed control chopper used as driver circuit, chopper converts the fixed and unregulated DC voltage in to variable regulated. Basically DC chopper compares the signal or voltage coming from the fuzzy controller, the fuzzy controller drives the chopper. The chopper. Connected with DC motor circuit diagram is shown in figure (2).

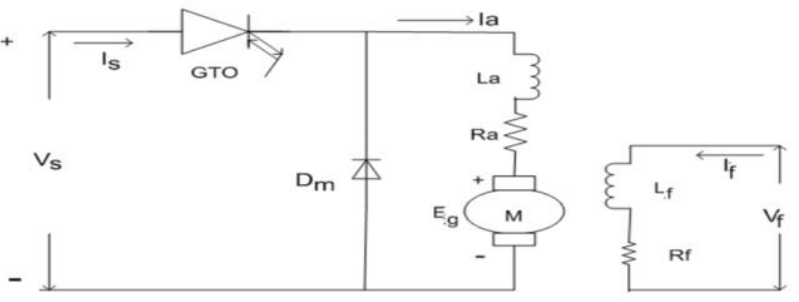

Figure 2: Shown Chopper fed SEDC motor

The armature current of SEDC motor is given by:

$$
I_{a}=\frac{V_{a}-E_{g}}{R_{a}}
$$

The average output voltage of chopper which fed DC motor calculated by:

$$
V_{\text {avg }}=\frac{1}{T} \int_{0}^{T} V(t) d t=K V_{m}
$$

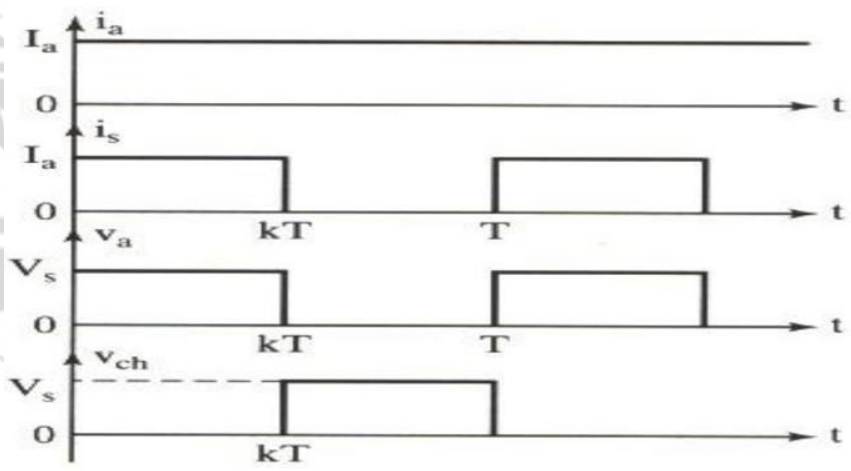

Figure 3 V-I characteristic of chopper

The calculation of average output voltage for armature DC motor is given by:

$$
\begin{aligned}
& V_{\text {avg }}=\frac{\text { Ton }}{\text { ton }+ \text { Toff }} V_{s} \\
& V_{\text {avg }}=K V_{s}^{\text {Or }}
\end{aligned}
$$

Where $\mathrm{K}$ is represent the duty cycle.

\subsection{Speed Control}

The meaning of speed control is an internal change of drive speed to a value required to execute the specific job, the concept of speed control is rising due to change in load on the DC motor shaft. So in much application system we need specific constant speed with change in load. The speed of DC motor given by the relationship.

$$
N=\frac{V-I_{a} R_{a}}{K \emptyset}
$$




\section{International Journal of Science and Research (IJSR) \\ ISSN (Online): 2319-7064 \\ Index Copernicus Value (2013): 6.14 | Impact Factor (2015): 6.391}

Armature terminal voltage and external resistance in armature circuit change affects armature circuit and the flax per pole $\phi$ involves change in magnetic field.

\section{Fuzzy Logic Controller}

Fuzzy logic control is control method based on linguistic control strategy, which collected from expert knowledge in to an automatic control strategy, the basic operation of fuzzy logic control is depends on good knowledge about the system to be controlled. Its solve problem rise from some plant are defaulted to represent in mathematical model, also in some plant to design the approaches mathematical model you must neglect some parameter. This problem effect on the robustness and sensitivity of control system, on the other hand the fuzzy logic controller does not need any mathematical model, and it's depending on human expert knowledge.

First introducing of fuzzy set theory in 1965 by Zadel to express and process fuzzy knowledge, there is strong relationship between fuzzy logic and fuzzy set theory. Figure (4) shown the structure of fuzzy control.

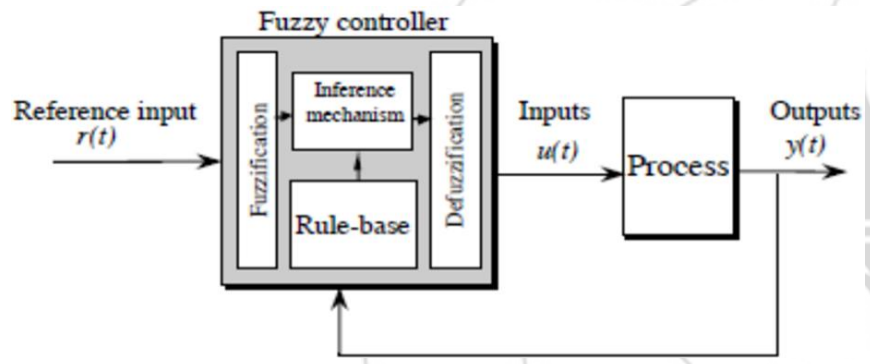

Figure 4: Shown the structure of fuzzy control.

The goal using FLC in this study is to improve the transient response and minimize speed control error, the controller output gain depends on error and change of error which plays important role to determine the controller input. FLC uses error and change of error for linguistic variables which generated from the control rules.

\section{MATLAB/Simulink}

5.1 Matlab/Simulink model of SEDC motor with PID controller

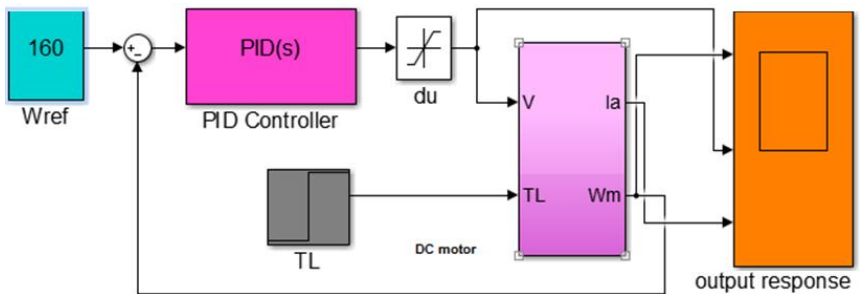

Figure 5 Mat lab/Simulink model of DC motor with PID controller

\subsection{Matlab/System model of SEDC Motor with Fuzzy} logic controller:

Figure (5) shows Simulink model of separately excited DC motor using chopper with fuzzy logic controller to control the speed of DC motor. It consists of DC motor fed by DC source the output of chopper circuit.

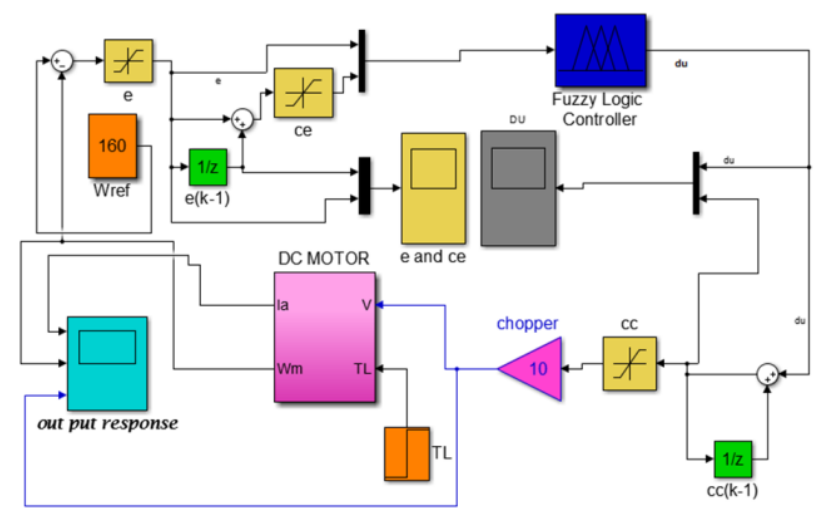

Figure 5: Mat lab/Simulink model of SEDC motor with fuzzy logic controller

\subsection{Fuzzy Rules}

In this paper we are developing fuzzy rules for seven membership function, as shown below:

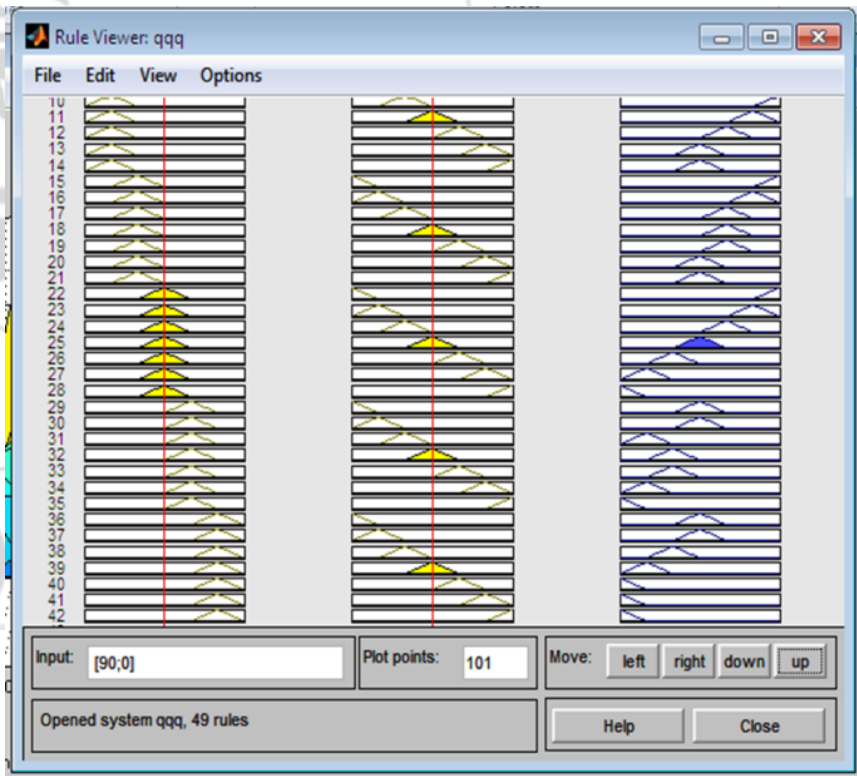

Figure 7: fuzzy rules for seven memberships

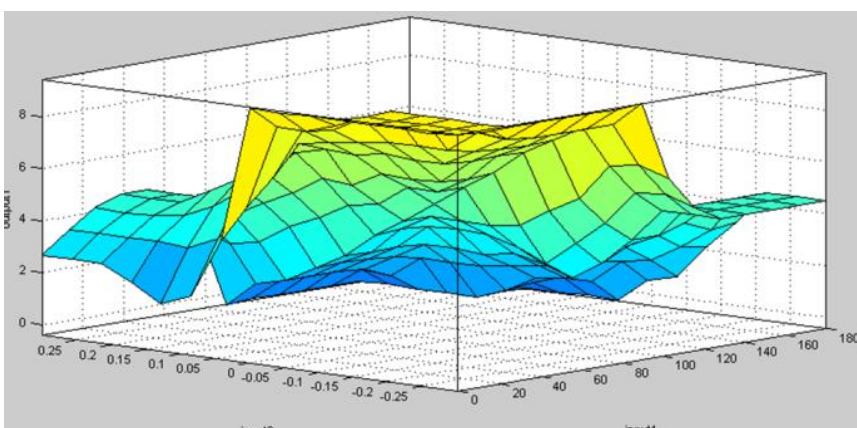

Figure 8: Surface structure of fuzzy rule 


\section{International Journal of Science and Research (IJSR) \\ ISSN (Online): 2319-7064}

Index Copernicus Value (2013): 6.14 | Impact Factor (2015): 6.391

\section{Results and Discussion}

A real parameter were used with separately excited DC motor, in Matlab /Simulink model as reference [12] model and find out Simulink responses for load torque. After that we used PID controller for same model of DC motor and same parameters, lastly fuzzy logic controller used for same model of DC motor and parameter. The parameter and Simulink response are shown below:

Table 1 show the parameter

\begin{tabular}{|c|c|}
\hline symbol & magnitude \\
\hline $\mathrm{Ra}$ & $0.5 \Omega$ \\
\hline $\mathrm{La}$ & $0.2 \mathrm{H}$ \\
\hline $\mathrm{Va}$ & $200 \mathrm{~V}$ \\
\hline $\mathrm{Jm}$ & $0.1 \mathrm{Kg} \cdot \mathrm{m}$ \\
\hline $\mathrm{Bm}$ & $0.008 \mathrm{~N} . \mathrm{m} / \mathrm{rad} / \mathrm{sec}$ \\
\hline $\mathrm{K}$ & $1.25 / \mathrm{rad} / \mathrm{sec}$ \\
\hline
\end{tabular}

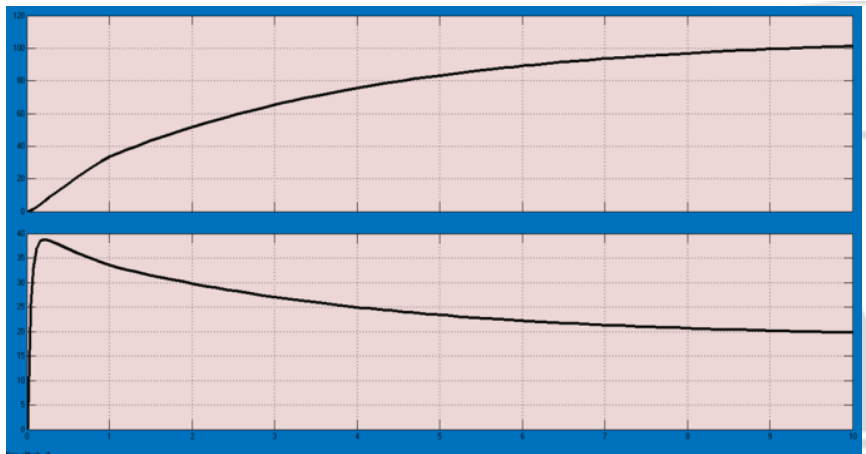

Figure 9 Simulink response of SEDC Motor without Load

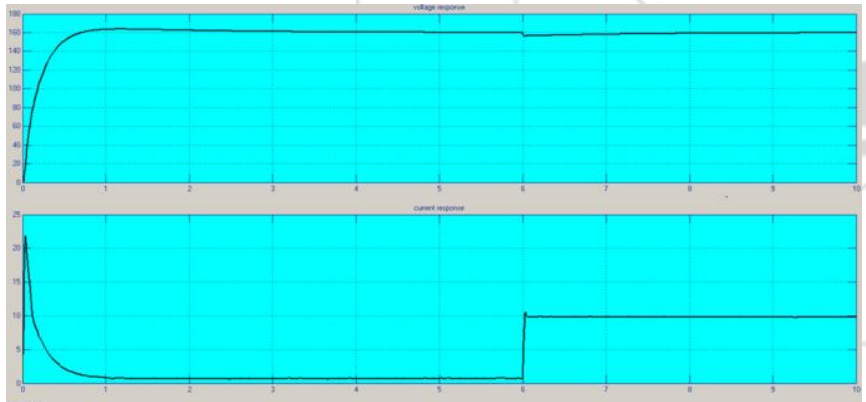

Figure 10: Simulink response of PID controller for TL $(2 \mathrm{Nm})$ and speed $(160 \mathrm{rad} / \mathrm{sec})$

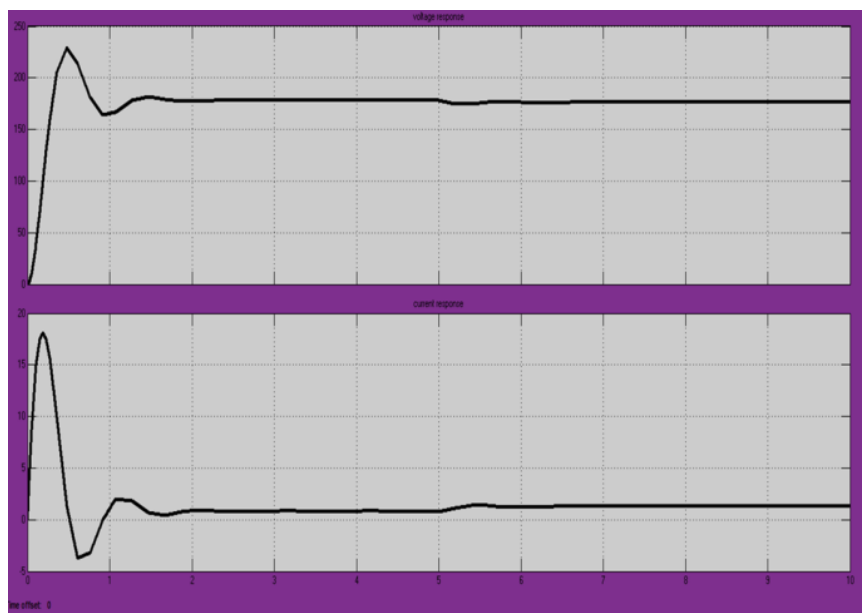

Figure 11: Simulink response of fuzzy logic controller for $\mathrm{TL}(2 \mathrm{Nm})$ and speed $(170 \mathrm{rad} / \mathrm{sec})$

\begin{tabular}{|c|c|c|c|c|}
\hline $\begin{array}{c}\text { Controller } \\
\text { used }\end{array}$ & $\begin{array}{c}\text { Rise time } \\
\text { (Tr) } \\
\text { In sec }\end{array}$ & $\begin{array}{c}\text { Settling Time } \\
\text { (Ts) } \\
\text { In sec }\end{array}$ & $\begin{array}{c}\text { Pesk } \\
\text { response } \\
\text { In \% }\end{array}$ & $\begin{array}{c}\text { Steady } \\
\text { state error }\end{array}$ \\
\hline $\begin{array}{c}\text { Conventional } \\
\text { PID controller }\end{array}$ & $0.52 \mathrm{sec}$ & $4.8 \mathrm{sec}$ & 180 & 0.1 \\
\hline $\begin{array}{c}\text { Fuzzy logic } \\
\text { Controller }\end{array}$ & $0.34 \mathrm{sec}$ & $1.8 \mathrm{sec}$ & 230 & 0.02 \\
\hline
\end{tabular}

The result shows that the fuzzy logic gives a better improvement to system response, when it used to control the speed of SEDC motor.

It depends on those rules were used and how it used. The main object in this paper is that after five second the system is loaded, the PID controller re-speeds in time equal $1.9 \mathrm{sec}$ and fuzzy logic controller in time equal .6sec.

\section{Conclusion}

In this paper the fuzzy logic controller is used to control the speed of SEDC motor, the MALAB/ SIMULINK were used to obtain the simulation results. The fuzzy logic controller was compare with conventional PID controller. The results show that the fuzzy logic controller provides better results than conventional PID controller for improve dynamic behavior of SEDC motor.

\section{References}

[1] ManafeddinNamazov and OnurBasturk, "DC motor position control fuzzy Proportional -derivtive controllers with different defuzzification methods" Turkish journal of fuzzy systems (elSSN:1309-1190), Vol.1, No.1 pp. 36-54, 2010.

[2] Wang Xiao-Kan, Sun Zhong-liang, Wanglei, feng Dongqing, " Design and Research Based on Fuzzy PIDParameters Self-Tuning Controller with MATLAB," Advanced Computer Theory and Engineering , International Conference on, pp. 996-999, 2008.

[3] Romeo U. Parrazales et al "a fuzzy logic controller applied to aDC. Motor" IEEE, pp. 653-6566, 2008.

[4] M.M.R. Ahmed et al "fuzzy logic speed control of d.c. motors fed by single-ended primary inductance converters (sepic)" IEEE, pp.343-347, 2008.

[5] Moley Kutty George. Et. Al, speed control of separately excited dc motor . American Journal of applied sciences 5 (3) Science Publications ISSN 1546 - 9239 -pp. 227 233, 2008

[6] J. Zhang, N . Wang and S Wang, Developed method of tuning PID controllers fuzzy rules for integration process , Proceedings of American control conference, Boston , 2004 , pp. $1109-1114$,

[7] K. H. Ang , G. Ch0ng and Y. Li , PID controller system analysis, design and technology, IEEE transaction on control system Technology, Vol. 13, No . 4 ,2005, pp. 559- 576.

[8] Gopal , M. control systems - principles and Design .3rd Edition, New Delhi: Mc Graw - Hill , 2008.

[9] Prabha Malviya(PG Student), Menka Dubey (Sr. Asst. Prof) International Journal of Engineering sciences and Research Technology. 


\section{International Journal of Science and Research (IJSR) \\ ISSN (Online): 2319-7064}

Index Copernicus Value (2013): 6.14 | Impact Factor (2015): 6.391

[10] Wasif Abdel Aziz Saluos, Mohammed Abdel Karatim Alia American journal of software Engineering and Applications Vol.3 No. 6. 2014, pp. 102-105.

[11]Lokesh Kumaral .International journal of Recent Research aspects ISSN :2349.7688, vol. 1, Issue 3, December 2014. pp. 49-55.

[12] Shashi Bhushan Kumar, Mohammed Hasmt Ali, Anshu Sinha. International Journal of Scientific and Research Publication, Volume 4, Issue 7, July 2014, ISSN, 22503153.

[13] Kapil Raghuvonsi, Shilpam Saxena International Journal of Advanced Technology \& Engineering Research ,Volume 4, Issue 6, ISSN No:2250-3536.

[14] Mahesh Chandra Gang war, Dr. Pratibha Tiwari International Journal of science, Engineering and Technology Research (IJSETR), Volume 4, Issue 5, May 2015, ISSN:2278-778.

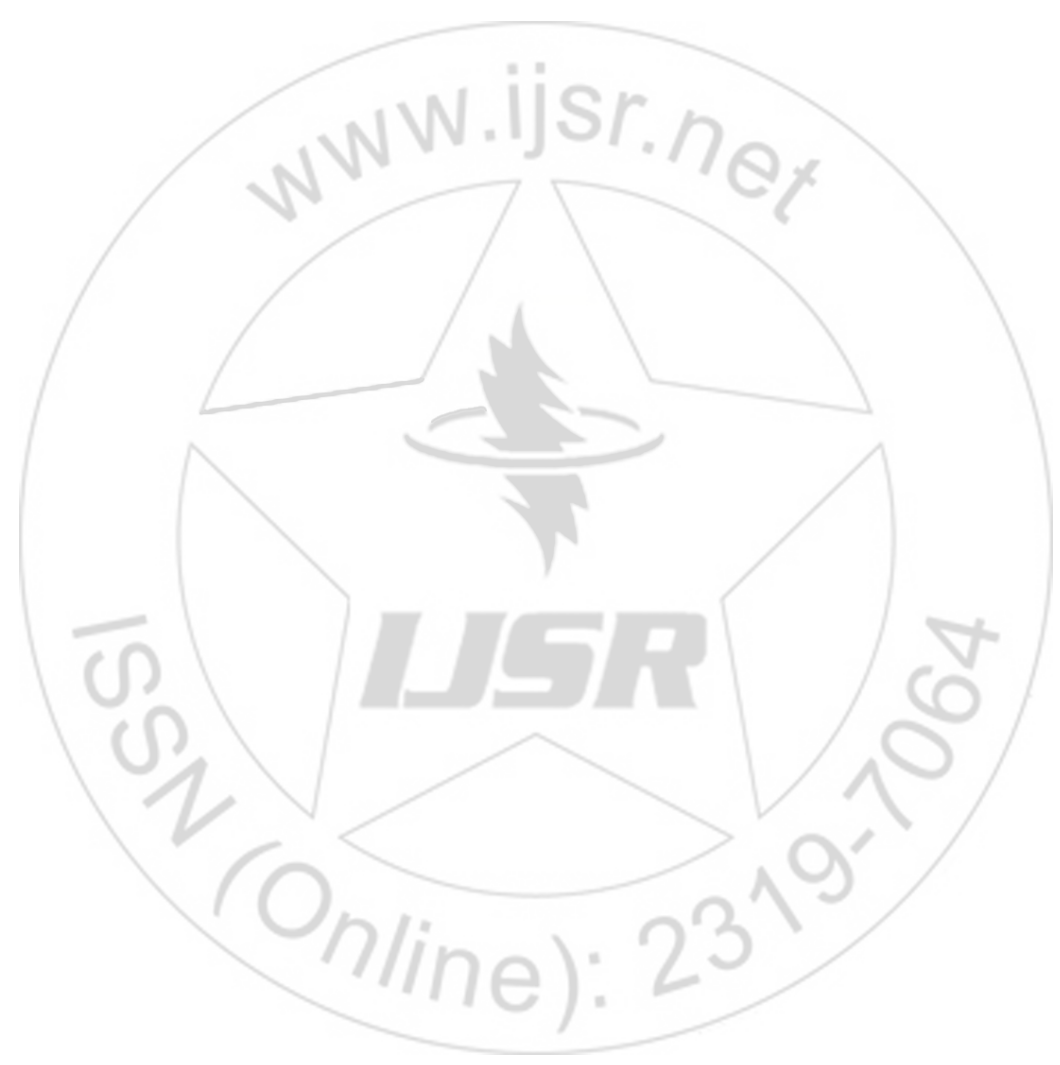

